\title{
The Practice, Dilemma and Countermeasure Analysis of State-owned Enterprise Human Resource Management Informationization
}

\author{
Zhang Ke \\ Beijing Normal University, School of government, Beijing, China \\ zhangkebnu@163.com
}

Keywords: state-owned enterprises; human resource management; informatization

\begin{abstract}
Enterprise human resource management informationization (e-HR) has gained achievements in the theoretical and practical fields in recent 40 years. By reviewing the theoretical development vein and practical experience of overseas and domestic e-HR, e-HR depends on the human resource management system and has the fast development speed in China and wide practical range, but it is encountered with the dilemma of insufficient foundation, lagging management and unreachable application effects. Based on a Chinese enterprise' experience in e-HR construction, implementation and application of SAP human resource system, its achievements and dilemma, the author proposes the countermeasures on the enterprise' dilemma and comes up with the feasible countermeasures on Chinese e-HR construction development.
\end{abstract}

\section{Overview of the State-owned Enterprise Human Resource Management Informationization}

In a broad sense, informationization comprehensively uses the information technology to fully develop the information resources and improve management efficiency and efficacy of each department and each industry. The informationization in the project management field is the application of the information technology in the project management. The model structure is shown as Fig 1:

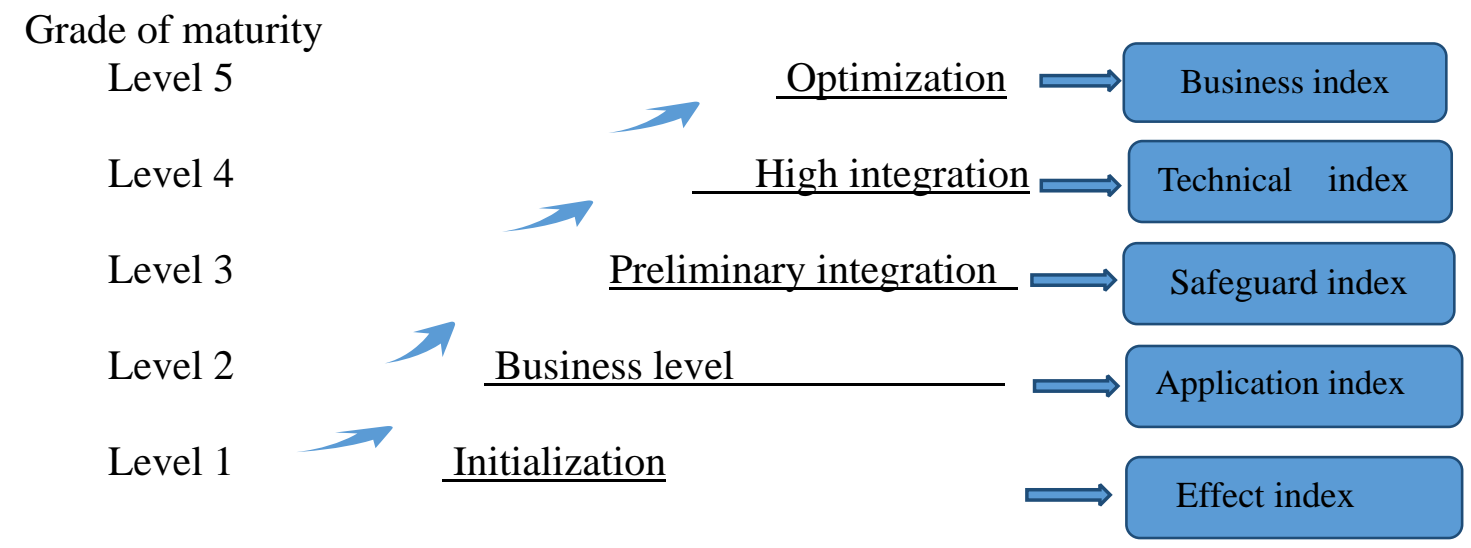

Fig.1 Maturity Model of Informatization Management

\section{The State-owned Enterprise Human Resource Informatization Construction Based on the Genetic Algorithm}

\subsection{The enterprise informatization construction model}

According to the Table 1, the enterprise informatization is established as:

$$
\mathrm{A}=\sum_{i=1}^{m} \alpha_{i} A_{i}
$$


Table 1 the Enterprise Informatization Performance Index System

\begin{tabular}{|l|l|}
\hline \multicolumn{1}{|c|}{ Informatization performance index } & \\
\hline Enterprise information construction level & A1 \\
\hline Enterprise network construction level & A2 \\
\hline Enterprise digitalization construction level & A3 \\
\hline Enterprise manager attention & A4 \\
\hline Enterprise organization integration & A5 \\
\hline Enterprise management system utilization & A6 \\
\hline $\begin{array}{l}\text { Information quality level of enterprise manager } \\
\text { and employees }\end{array}$ & A7 \\
\hline Enterprise personnel structure setting level & A8 \\
\hline $\begin{array}{l}\text { Enterprise personnel absorption training and } \\
\text { innovative level }\end{array}$ & A9 \\
\hline
\end{tabular}

Table Enterprise Informatization Construction Measures

\begin{tabular}{|l|l|}
\hline \multicolumn{1}{|c|}{ Informatization construction measures } & \\
\hline Establish the enterprise information institutions & B1 \\
\hline Increase computer hardware facilities & B2 \\
\hline Enhance enterprise network performance & B3 \\
\hline Establish enterprise database & B4 \\
\hline Establish enterprise website and e-commerce & B5 \\
\hline Reconstruct enterprise business process & B6 \\
\hline Train enterprise information technicians & B7 \\
\hline Enhance enterprise information innovation & B8 \\
\hline
\end{tabular}

$\mathrm{m}$ is the enterprise informatization level index; $\mathrm{Ai}$ is the ith enterprise informationization level index as 0 or 1; 1 stands for the high informatization level; 0 stands for the low informationization level; we can use the Analytic Hierarchy Process(AHP) to obtain the weigh $\beta$ i of each level index, obtaining:

$$
\sum_{i=1}^{m} \alpha_{i}=1
$$

According to Table, the enterprise informationization construction measure is established as:

$$
\mathrm{B}=\sum_{j=1}^{m} \frac{\beta_{j}}{\beta_{\text {sum }}} \beta_{j}
$$

$\mathrm{n}$ is the enterprise information construction measure category; Bj stands for the jth construction measure as 0 or $1 ; 1$ stands for implementing this measure; 0 stands for not implementing this measure; $\beta \mathrm{j}$ refers to the charge of implementing jth measure, making:

$$
\beta_{\text {sum }}=\sum_{j=1}^{m} \beta_{j}
$$

Therefore, there are two problems in enterprise informationization construction: enterprise informatization degree is the highest, namely:

$$
\operatorname{MaxA}=\sum_{i=1}^{m} \alpha_{i} A_{i}
$$

Secondly, enterprises have the smallest cost in the informationization construction, namely:

$$
\text { Min } \mathrm{B}=\sum_{i=1}^{m} \frac{\beta_{j}}{\beta_{\text {sum }}} B_{j}
$$

The informatization level $\mathrm{A}$ is changed with the implementation of the informatization construction measure $\mathrm{B}$, because some measures enhance the informationization level index, but 
weaken another informatization level index. We mark $A=f(B)$, showing that this is a multi-target optimization problem. The target weight and method can be used to construct an optimization target function, namely:

$$
\operatorname{MaxZ}=\mathrm{vA}-\omega \mathrm{B}
$$

or:

$$
\operatorname{MaxZ}=\mathrm{vf}(\mathrm{B})-\omega \mathrm{B}
$$

Among which, $\mathrm{v}$ and $\mathrm{w}$ are weights, showing the managers' preference to the target 1 and target $2(\mathrm{v}+\mathrm{w}=1,0 \leq \mathrm{v}, \mathrm{w} \leq 1), \mathrm{v}>\mathrm{W}$ shows that the manager pays more attention to the enterprise informationization construction; on the contrary, it shows that the manager pays more attention to the charge required by informatization construction.

\subsection{Solution of the genetic algorithm}

(1) The first step of the coding genetic algorithm is to stand for the solution for selection in a coding string. Each string is the feature of a series of value. Each feature value can be coded by using a value. This value comes from the set of the discrete value called as the equal value. According to the problems, we can use the binary vector as a chromosome to stand for the actual value of the single variable. For example, informatization level (110101110) shows that the enterprise's network construction level (A3), enterprise organization integration (A5) and enterprise employees' quality level (A9) are not high. These aspects should be further improved. The informatization construction measures (01001000) mean to increase computer hardware facilities and construct the enterprise website and e-commerce.

(2) When group $t=0$, several individuals are generated at random to constitute in a group $\mathrm{P}(\mathrm{t})$. the group stands for the set of possible solutions for optimization problems. In other words, the informationization construction can take several implementation schemes. Generally speaking, they are not optimal schemes. GA's task is to begin with these groups and simulate the evolutionary process and finally obtain the optimal scheme.

(3) After establishing the groups by evaluation, the next step is to calculate the conformity of each member in the groups, because each chromosome is the candidate of the optimal solution. In terms of a maximal problem, the conformity of kth member Fk is the point's estimated value of the target function in this parameter space. Here, we set up the conformity function as:

$$
\mathrm{F}_{\mathrm{k}}=\mathrm{v} \sum_{i=1}^{\mathrm{m}} \alpha_{i} A_{i}-\omega \sum_{j=1}^{\mathrm{m}} \frac{\beta_{j}}{\beta_{\text {sum }}} B_{j}
$$

(4) Selection In this stage, we need to construct a new group $\mathrm{P}(\mathrm{t}+1)$ in the current generation; select the operation to determine which father chromosome will participate in multiplying the next generation. The commonest method is to set up the selective probability:

$$
\mathrm{P}_{\mathrm{i}}=\mathrm{F}_{\mathrm{i}} / \sum_{k=1}^{\lambda} F_{k}
$$

Among which, $\lambda$ is the group size; Fi is the conformity of the ith chromosome.

\section{The Enlightenment and Countermeasures of State-owned Enterprise Human Resource Informatization Management}

\subsection{To set up the modern informatization human resource management view from top to bottom}

e-HR construction is imperative in enterprise management activity, while relatively large investment determines that this project must have the decision-making support to be successfully developed. The human resource informatization effect is firstly determined by the decision-making thought cognition and the assigned development strategy. From the perspective of informatization effect, the most important is to establish the modern human resource management informatization concept and define the e-HR target and enterprise management role fundamentally. It promotes and provides the sufficient human power, financial power and technical resources from the strategic 
height. The publication of the human resource management system and operation can't be equal to the human resource management informatization. If informatization range and level can't satisfy the increasingly improving human resource management informatization, we can't think that the enterprises realize the human resource management informatization. As a result, Chinese enterprises should promote the human resource management informatization from the strategic height to practical level, from system safeguard to practical operation and from top to bottom.

\subsection{To use the development insight to treat with the human resource informatization construction and implement strategic thought.}

Modern enterprise human resource management requirements are not changed, but are dynamic and constantly developed. On the one hand, enterprises' internal and external environment is constantly changing. Industrial development tendency, economic situations, enterprise life cycle, market status and development prospect, enterprise management level, enterprise scale and talent teams affect enterprise human resource management requirements, thus we must use the development insight to dynamically treat with e-HR construction. On the one hand, enterprise-HR construction is restrained by the internal and external factors. For example, when the strategy is established under the certain precondition of "man", "finance" and "system", how to continuously improve the human resource management informatization level under the conditions of existing technical means, personnel scale and expenditure support is the most important of e-HR implementation. Based on Chinese e-HR experience, the institutional safeguard, personnel and technical support, reinforcement of training and exchange, system updating and subsequent development are feasible modes.

\subsection{To improve localization of the human resource management system and individualization level}

There is no general management principle around the world. Similarly, it is impossible to have the same internal and conditional conditions and enterprise demands in e-HR construction process. Chinese enterprise management culture and western developed countries have lots of difference. Since modern human resource management mode and means were introduced, it has constantly experienced the local reform. As the necessary road to improve the modern enterprise human resource management level, the informatization design philosophy of e-HR construction must conform to the Chinese cultural traditional and enterprise management habits. In addition to economic tendency, social culture and enterprise development stage, Chinese enterprises, ownership form, enterprise model, industry and enterprise culture also will have different requirements for e-HR system, thus the individualization of the human resource management system is extremely important. In selection of management instruments, system transformation, updating, maintenance and operation process should fully consider the special situation and development demands of enterprise.

\section{Conclusions}

To sum up, in the state-owned enterprise human resource management, informatization application can effectively improve the management efficiency and make management more scientific. In the future development process, informatization is a development tendency and it should be valued by state-owned enterprise human resource management.

\section{References}

[1] Liu Yuan, Practice and Reflection on State-owned Enterprise Human Resource Informatization Construction [J], Enterprise Reform and Management, 2016(06): 54.

[2] Zhong Wenbiao, Large-scale State-owned Enterprise Human Resource Management Informatization System Construction and Application [J], Contemporary Petroleum and Petrochemical, 2017, 25(01): 34-39. 
[3] Yu Xinge, Discussion on State-owned Enterprise Human Resource Informatization Construction [J], Modern State-owned Study, 2015(08): 39+41.

[4] Hu Qilin, Practice and Reflection on State-owned Enterprise Human Resource Informatization Construction [J], Economist, 2012(06): 231-232. 